\title{
3 INFORMATION SYSTEMS IN ORGANIZATIONS AND SOCIETY: Speculating on the Next 25 Years of Research
}

\author{
Steve Sawyer \\ Pennsylvania State University \\ Kevin Crowston \\ Syracuse University
}

\begin{abstract}
The community of scholars focused on information systems in organizations and society (the IFIP 8.2 community) has grown in number, voice, and influence over the last 25 years. What will this community contribute during the next 25 years? We speculate on two possible areas: more articulate conceptualizations of information systems and more detailed socio-technical theories of their effects. For both of these possibilities, we project forward from the historical trajectory of the IFIP 8.2 community's involvement. Like all speculative scholarship, our argumentation is more about imagining possible directions than arguing the superiority of one particular view relative to all others. This considered speculation is directed at both stirring the community's collective mind and advancing the value of this community's work to interested others.
\end{abstract}

\section{INTRODUCTION}

The community of scholars focused on information systems in organizations and society ${ }^{1}$ has grown in number, voice, and influence over the last 25 years. In this paper

${ }^{1}$ This is known here as the IFIP 8.2 community. By IFIP 8.2 we mean the International Federation on Information Processing's (IFIP) Technical Committee 8 (information systems) Working Group 8.2 (information systems in organizations and society). The community has grown to be about 300 members and friends with about 60 percent who are not in North America. 
we presume to look ahead and ask: What will this community contribute during the next 25 years? Responding to this question, in this paper we propose two areas where the IFIP 8.2 community of scholars might make a particular contribution: better conceptualizations of information systems and more detailed socio-technical theories of their effects on organizations and society.

To provide context we begin with a brief introduction to the intellectual geography of the IFIP 8.2 community. In doing this we identify six contributions of the contemporary IFIP 8.2 scholarship. We then introduce and discuss two candidates for the IFIP 8.2 community's consideration as particularly promising opportunities for future research. Our two candidates (conceptualizing IS and socio-technical theorizing) hold particular promise. Clearly, however, the members of the IFIP 8.2 community will engage (and lead) in numerous other opportunities such as methodological innovations, the broadening of viable research domains for IS research, adapting and using social theories to study IS, and championing broader (non-Popperian) views of science in IS research (e.g., Dutton 1999).

\section{THE INTELLECTUAL GEOGRAPHY OF THE IFIP 8.2 COMMUNITY}

The IFIP 8.2 community roots can be traced to meetings held in the early 1980s by a dedicated group of scholars, which led to the milestone 1984 Working Conference held in Manchester, UK, The scholars at these early meetings, many of whom also attended the 1984 conference, came primarily from Europe and the UK, from a variety of disciplines, and shared an interest in the mutually interdependent nature of the effects and influences of information systems, organizational operations, and social life. Contemporary IFIP 8.2 efforts and its charter reflect the energy of the early 1980s to legitimize scholarly attention on the study of information systems in organizations. ${ }^{2}$

The specific efforts of the early members of IFIP 8.2 suggests that they had a different vision of the IS field than did the early ICIS organizers (e.g., Keen 1980). The scholars who helped to found IFIP 8.2 explicitly linked their interests to the burgeoning presence of information systems in organizational and societal contexts. They espoused through their works a willingness to use what are now known collectively in the IS community as intensive research methods. ${ }^{3}$ The early members of the IFIP 8.2 community focused on theory-building research and did their work in a wide range of settings (homes, hospitals, schools, public sector units, and small businesses). These scholars can now be found in business schools, information science schools, and a wide range of computing- and information-oriented schools.

See http://www.ifip.org and http://www.ifipwg82.org for more information.

${ }^{2}$ This growing interest was also signified by the first International Conference on Information Systems (ICIS) in 1980. The ICIS and IFIP8.2 communities overlap and their growth is interconnected.

${ }^{3}$ Intensive research methods include field-based studies employing case study and ethnographic techniques, hermeneutic approaches, and textual analyses. See Lee (1997) and Weick (1984). 
Conversely, the mainstream of the ICIS community has tended to focus on large, for-profit, organizations (e.g., the Fortune 500). ${ }^{4}$ The ICIS community has tended to embrace experimental (or quasi-experimental) research approaches and emphasize theory-testing research. Since 1980, the ICIS community has grown to number 2,300 people, with more than half located in North America. ${ }^{5}$

Both the ICIS and IFIP 8.2 communities are weakly tied to information science, sociology, communications, medical informatics, and public administration disciplines - where studies of the effects of information systems and organizations are also conducted (e.g., Ellis et al. 1999). This disconnect suggests that creation and maintenance of community identity, an important part of the last 25 year's effort by both the IFIP 8.2 and ICIS communities, may have come at the expense of connecting to likeinterested research communities.

\section{SUMMARIZING THE IFIP 8.2 COMMUNITY'S CONTRIBUTIONS}

As a starting point to understanding the distinctive characteristics of the IFIP 8.2 community's contributions, we draw on the 23 edited proceedings of the IFIP 8.2 working conferences as an archive of the community's research output. While the IFIP 8.2 community's intellective production and intellectual contributions extend far beyond these specific books, they provide a window into the community's heart. Jones (2000) and Sawyer and Chen (2002) have, for different purposes, both reviewed this collection. Beyond that, Lee and Liebenau (1997) provide some interim reflections (on method, particularly). The editorial comments in each of these edited books highlight the ongoing discourse, current issues, and place in the community's trajectories of interest.

From these analyses of the IFIP 8.2 collected volumes, we identify and discuss six characteristics: (1) an orientation towards social theories, (2) dominant conceptualizations of information and technology and a common level of analysis, (3) an orientation toward the use of intensive research methods, (4) use of critical and analytical perspectives in research, (5) an openness to a range of research settings, and (6) an open discourse on the study of IS in organizations and society.

\subsection{An Orientation Toward Social Theories}

By social theory, we mean here theories that take into account the relations among individuals or collections of individuals. Social theories further reflect the presence of enduring social relations, their effects, or the nature of these effects. The IFIP 8.2 literature often draws on social theories, for example, those of Latour, Giddens, Habarmas, and others (Jones 2000). Jones notes that over the last 25 years a variety social theories have been drawn into the IFIP 8.2 community and adapted for specific

\footnotetext{
school.

${ }^{4}$ This seems to reflect that the primary academic home for many ICIS scholars is a business

${ }^{5}$ Here we use the subscription numbers to the ISWORLD listserv as a surrogate measure of this community. See http://www.isworld.org.
} 
attention to IS (e.g., Walsham 1997). He also notes that the use of social theory is uncommon (found in less than 5 percent of papers) in the broader IS literature, which is dominated by individualistic theories of human behavior (Lamb and Kling 2003; Sawyer and Chen 2002).

\subsection{Dominant Conceptualizations of Information and Technology and Common Levels of Analysis}

Sawyer and Chen's (2002) analysis of the IFIP 8.2 literature indicates that this body of research has several common conceptualizations. For example, information is often conceptualized as embedded in a web of people and their uses of ICT. That is, information arises from discourse and cannot be removed from the people and context in which it occurs. Technology $(I C T)$ is most often conceptualized as ensembles of artifacts and people and represented in functional, or use-based, analyses. This functional analysis is often done by juxtaposing findings of use with design intentions of the ICT.

The common levels of analysis in IFIP 8.2 research are organizational or social and there is an explicit linking between individual actions and the larger social context. In this view, people are social actors (Lamb and Kling 2003), having some, but not complete, individual agency and living and acting within a shifting set of social norms that, while fluid, shape behavior in both subtle and direct ways. The contextual nature of this work means that the level of analysis is explicitly tied to a larger context. As Avgerou (2002) notes, the social and organizational contexts of ICT use are often conceptualized as institutions. By institutions we mean here enduring social structures that can be both stable and changeable (e.g., Agre 1999, 2000, 2003; Scott 2002).

\subsection{An Orientation Toward Intensive Methods}

The IFIP 8.2 community is one of the primary forums in IS for field work, ethnography, hermeneutics, action research, critical analysis, and a range of research methods that do not rely on inferential statistics, simulations, computer modeling, etc. Exemplars and discussions ofthese intensive methods have been showcased in the 1985 , 1991, and 1997 edited proceedings (see Jones 2000). Lee and Liebenau (1997, p. 5) further note that "all Working Conferences of IFIP 8.2 are about qualitative research."

\subsection{Critical and Analytical Perspectives}

The IFIP 8.2 research often takes a critical or analytic perspective, eschewing normative angles. The critical perspective is one that examines the roles, values, uses, and purposes of ICT without automatically and uncritically accepting the goals and beliefs of the groups that commission, design, or implement specific ICTs (e.g., Wastell 2002). An analytical perspective is one that leads to developing theories about ICTs in institutional and cultural contexts, or to doing empirical studies that are organized to contribute to such theorizing (e.g., Richardson 2003). In contrast, a normative perspective to research is one whose aim is to recommend alternatives for professionals who design, implement, use, or make policy about ICTs. 


\subsection{Openness to a Range of Research Settings}

The IFIP 8.2 community's research reports on the roles of information systems in a wide range of settings: developing countries, education, military, small and medium enterprises, faith-based organizations, formal and informal communities, online milieus, public sector/government and larger social settings. ${ }^{6}$ This broadened view of acceptable settings for studying the roles, functions and purposes of ICT provides verdant territory for theorizing on the institutional nature of ICTs (as we discuss in more detail in the next section).

\subsection{An Open Discourse}

This final characteristic reflects the IFIP 8.2 community in its openness to diverse views on, and approaches towards, IS research. Over the past 25 years, there has been explicit attention to recruiting new members via workshops and working conferences. Concurrently, there has been an explicit educational agenda to provide alternative conceptualizations, research methods, and domains to study IS. The IFIP 8.2 scholarly discourse has also focused on understanding and theorizing on IS, and not focused on falsification and hypothesis testing (which often characterizes IS research). In this acceptance of intellectual plurality and anomaly, the IFIP 8.2 community reflects more a Kuhnian, ${ }^{7}$ rather than a Popperian, view of science.

In summary, and like others, we assert that these six characteristics of the IFIP 8.2 research, and the evolving and growing community of scholars producing the work, have influenced the larger field of IS to accept these contributions (Markus 1997). In contrast, Jones notes that very little of the larger IS community research draws on the theory base that the IFIP 8.2 community uses. Sawyer and Chen note that the IFIP 8.2 conceptualizations of technology and people represent a small percentage of the work published in premier IS research outlets. They also note that much of this work speaks more to the organizational and social context than it does about the nature and form of the ICT and IS in these contexts.

The IFIP 8.2 community's research may be influencing the larger IS discourse, but we speculate that this influence is limited (or at least should be larger and more profound than its current levels). The last 25 years of work in IFIP 8.2 has been driven in part by twin desires. One desire has been to shape the larger discourse. A second desire has been to provide a forum for those who take on critical stances, social theories and intensive approaches to IS work. The successful efforts to legitimate IFIP 8.2 as a community within IS over the past 25 years provides us the current opportunity to focus more on shaping the future discourses on IS.

With this as context, we return to our formative question: Over the next 25 years, what should the community of IFIP 8.2 scholars contribute to IS research and, more broadly, society? Underlying this question is the belief that our community needs to be

\footnotetext{
${ }^{6}$ As mentioned above, much of the IS community has generally focused on private sector corporations (exemplified by Fortune 500 companies).

${ }^{7}$ Or perhaps a Bourdiean view....
} 
more than an intellectual home for those taking on different approaches to the conduct of IS research, examining unique and underexplored domains, and privileging social theories. ${ }^{8}$ Communities have aspirations and these aspirations must both excite the members and extend beyond self-preservation. For the IFIP 8.2 community, it seems these aspirations take form as opportunities to continue shaping the academic discourse on, and society's understanding of, the roles and values of ICT.

\section{TWO OPPORTUNITIES FOR THE IFIP 8.2 COMMUNITY}

We focus in the balance of this paper on two particular opportunities. These represent the confluence of our community's intellectual trajectories, scholarly strengths, gaps in the larger discourse on information systems, and the needs of society. The first opportunity is to examine more critically and publicly the meanings and features of ICT. An important contribution of the larger IS community (and we include the IFIP 8.2 scholars as a part of this larger group) is to help science and society understand what it means to have and use ICT. Orlikowski and Iacono (2001) argue that ironically the IS field has paid little attention to conceptualizing its core artifact. Sawyer and Chen (2002) note that the IFIP 8.2 community specifically has focused more on the ways that social contexts shape the development, deployment, and use ICT than on specific meanings and features of the ICTs being studied.

The IFIP 8.2 community's research focus (and its strength) has been cross-level, context-embracing, and, while imprecise as a term, "wide-angle" scholarship on the nature and meanings of social and organizational structures in which ICT exist, and in the intertwined roles of ICT within organizations and society. Raising the level of attention on the meanings and nature of computing in these settings is the right next step because it specifically fits the IFIP 8.2 community's intellectual trajectories, the group's research strengths, fills gaps in the larger IS discourse, and addresses the needs of society.

That is, the IFIP 8.2 community's orientation to theory-building use of intensive methods, and attention to a broad discourse provides the basis for moving forward our theorizing on the nature and meaning of ICT. We speculate that the IFIP 8.2 community's theory-building orientation means that members are likely to be interested in the role of theory development around ICT and have methodological skills to pursue this effort. Further, we assert that this theory building orientation will be aided by the community's social norm of open discourse, meaning that those who take on ICT theorybuilding will find a venue and community to both critique and support their efforts.

The second opportunity we see for the IFIP 8.2 community is to continue to extend and better articulate our theories and concepts of the socio-technical nature of ICT. ${ }^{9}$

\footnotetext{
${ }^{8}$ In saying this, we make explicit the need to both continue being an institution that balances shared interests and individual autonomy. We are suggesting opportunities to develop shared interests, not prescribing particular futures.

${ }^{9}$ Mumford (2000) noted that the early work by scholars in IFIP 8.2 relative to socio-technical theorizing has faded from more recent discourse.
} 
Work in this area often draw from related literature in science and technology studies (for example, Bijker 1995; Giddens 1984; Hughes 1987; Latour 1987) to explore the ways in which technologies are formed, influenced, and adapted by the social milieus in which they exist. However, Baskerville and Myers (2002) have argued that IS may now be in a position to articulate its own theories and thus become a reference discipline for others interested in the use and effects of ICT. And, we seeing glimpses of sociotechnical theories explicitly developed toward ICT from friends of IFIP 8.2 (e.g., Kling and McKim 2001).

The IFIP 8.2 community's interests in social theories and its role in understanding and explaining the roles that ICT play in organizations and society suggest that there is interest in developing better socio-technical theories of ICT. Our community's theorybuilding orientation, expertise in intensive methods, and the norms of open discourse further suggest that our community is well-positioned to take on socio-technical theorizing. Moreover, when combined with the first opportunity (to better theorize on ICT), it may be that the two opportunities can, for some in the IFIP 8.2 community, be self-reinforcing.

\subsection{Opportunity One: Better Conceptualizing ICT}

The first opportunity for the IFIP 8.2 community is to focus on better developing the concepts and constructs of ICT. We focus on conceptualizing ICT because, for at least two reasons, the study of IS is also the study of ICT. First, ICT is central to essentially all contemporary IS and certainly to those that have more than a local effect. Second, much of the growth in the use and value of IS can be attributed to the increased power of the underlying ICT.

\subsubsection{Conceptualizing ICT}

In suggesting a focus on conceptualizing ICT, we build on Orlikowski and lacono (2001) who identified five general approaches to conceptualizing ICT in the scholarly discourse on IS: (1) as a tool or set of features, (2) as an ensemble or a set of functions, (3) via some proxy, (4) as a computation, or (5) not at all (a nominal approach). ${ }^{10}$ In Appendix A we briefly discuss each of the characterizations of ICT relative to what it means for conceptualizing an IS. In the rest of this section we outline current conceptualizations of ICT in the IFIP 8.2 community, explain why this opportunity is worth collective interest, and suggest a path forward.

\subsubsection{Current Conceptualizations of ICT in the IFIP Community}

Sawyer and Chen's (2002) analysis of the IFIP 8.2 literature reveals that 55 percent of the papers published in the IFIP 8.2 conference proceedings between 1984 and 2000

${ }^{10}$ Other approaches such as Taylor's $(1982,1986)$ value-adding model of ICT or Henderson and Cooprider's (1990) functional model of ICT are also viable bases for this theorizing. We focus on Orlikowski and lacono's (2001) approach because it reflects the most recent and most broad-based effort to categorize approaches to theorizing ICT. 
represent ICT as either a proxy or as presence/absence. In other words, a bit more than half of the papers have little to say about the details of the ICT. ${ }^{11}$ Simply, the focus has not been on ICT; it has been on the context around ICT. The remaining 45 percent of the papers characterize ICT (and the larger IS) as either collections of features or as functional ensembles. We therefore focus on these two later approaches and especially on the linkage between these views as a starting point for building richer conceptualizations of ICT.

Functional conceptualizations of ICT differ from feature-based views in the level of abstraction (Henderson and Cooprider 1990; Taylor 1982, 1986). Feature-based conceptualizations detail the design intentions of an ICT and focus on the direct or intended effects of particular elements of an IS or the ICT in an IS. Functional conceptualizations focus on the ways in which ICT get used. Functional models of ICT provide a means to better assess new technologies and compare across existing technologies. By explicitly linking the ICT and people's uses, the focus of the approach is on empirical studies of use and the intended and unintended consequences of use. For example, and building on Taylor (1986), Sawyer and Tapia (2003) document five functional uses of ICT: to support personal or institutional production, to allow for control, to provide access to information, to enable coordination, or to entertain. They do not, however, link this functional conceptualization to any particular set of features, leaving open the means to translate their functional view into specific feature sets.

\subsubsection{Towards Richer Conceptualizations of ICT}

Given the underlying differences among feature-based and functional conceptualizations of ICT (and IS), it is often difficult to reconcile the findings from these studies. Studies that present functional depictions of computing packages do not easily map to specific features. Likewise, specific features of an IS are not easily mapped to their functional uses (e.g., Taylor 1982, 1986), Scholarship that explicitly focuses on these relationships among uses by users leads to identifying key elements of a functional view of ICT (i.e., Palen 2003). Further, studies that explore the differences in intention and use from a feature-based view of ICT (as is common in studies of human-computer interaction) are steps toward reconciliation. Whatever the path, the opportunity is to develop a means to bridge these two approaches. A trajectory of research that will help bring together the findings from these two approaches may lead to additional conceptualizations of ICT, to a means of translating or relating differing views, and to discourse on the assumptions, methods, and problems tied to each of the two current conceptualizations. A more robust conceptualization of ICT, one that links features of a particular form to their functional uses, would enable professionals in practice to make better decisions on the value and effects of new IS. Likewise, conceptualizations of ICT that allow us to combine or bridge feature and function perspectives will lead to stronger theories of use, value, and outcome.

${ }^{11}$ There was virtually no proof-of-concept work published in the IFIP 8.2 literature. This is not surprising given the community's focus on the social aspects of IS rather than building IS. 


\subsubsection{Why this Opportunity?}

There are two reasons why the IFIP 8.2 community is particularly well positioned to engage this work. First, the adoption of a critical and analytic perspective has led scholars in this community to conceptualize technology in use, rather than taking as authoritative the intended purposes of the technology. Second, the IFIP 8.2 community's use of intensive methods provides access to the types of rich data that will be needed for the work of conceptualizing activity that theory-building around ICT will require. In doing this we anticipate that out theorizing on ICT will broaden (perhaps extending current Orlikowski and lacono depictions) our means of representing what an IS is and means.

\subsection{Opportunity Two: Developing Socio-Technical Theories of IS Effects}

The second opportunity we see for attention by the IFIP 8.2 research community is to more explicitly pursue the arrangements, interactions, and elements of socio-technical theorizing relative to IS. Weick (1995) argues that theorizing is a process, while theory is an outcome of that process. He further notes that theorizing is often not visible, but should be.

\subsubsection{Why this Opportunity?}

Scholars generally accept that IS are socio-technical, although there seems to be little systematic attention paid to the arrangements, interactions, and elements of this socio-technical relationship (Bostrom and Heinen 1977a, 1977b; Mumford 2000). The acceptance stands unquestioned and underdeveloped, separated from the main discourses of IS and mostly outside the main discourses of socio-technical scholars. The IFIP 8.2 community, known for its open discourse, uses of social theory, and theorybuilding orientation, seems well-positioned to pursue more explicit theorizing on the relations among the social and the technical.

\subsubsection{Towards Richer Conceptualizations of ICT Effects}

There are a number of different conceptualizations of socio-technical research, many of which have been successfully applied to studies of ICT, such as actor-network theory, structuration theory, social shaping of technology, social construction of technology, and institutional approaches. ${ }^{12}$ Socio-technical theories focus on the multiple, intricate, and evolving links among social and technical elements and helps to highlight how these elements exist in relation (not independently) ofone another. As we outline below, Bijker's (1995) four principles of socio-technical change theory help illustrate the generic goals and the theoretical tensions that exist in socio-technical

\footnotetext{
${ }^{12}$ For more information on these approaches, see MacKenzie and Wacjman (1999).
} 
research: (1) the seamless web principle, (2) the principle of change and continuity, (3) the symmetry principle, and (4) the principle of action and structure.

(1) The seamless web principle states that any socio-technical theory of ICT should not a priori privilege technological or material explanations ahead of social explanations, and vice versa.

(2) The principle of change and continuity argues that socio-technical theories of ICT must account both for change and for continuity, not just one or the other.

(3) The symmetry principle states that the successful working of a technology must be explained as a process, rather than assumed to be the outcome of superior technology.

(4) The actor and structure principle states that socio-technical theories of ICT should address both the actor-oriented side of social behavior, with its actor strategies and micro interactions, and the structure-oriented side of social behavior, with its larger collective and institutionalized social processes.

While Bijker's principles provide a set of ideals for socio-technical research to strive for, in practice they illustrate tensions to be managed in the research process. Specific studies of ICT and IS using the socio-technical perspective will vary depending on

- the degree to which they focus on technological processes and technological features versus social processes and social objects versus balancing both (seamless web)

- the degree to which they focus on processes of change versus continuity with the past and maintenance of existing processes versus balancing both (change and continuity)

- the depth of description and explanation in the socio-technical change process, ranging from thick or rich descriptions of an ICT to relatively thin associations between outcomes and various success factors (symmetry)

- the degree to which they focus on action-oriented aspects of social behavior, such as actor strategies and interests, versus structural aspects of social behavior such as institutional processes (action and structure)

A socio-technical perspective on ICT leads us to argue that ICT are simultaneously a technological and social phenomenon, and that theories of ICT should address both of these aspects. A socio-technical perspective also provides a means to organize and critique existing research. The IFIP 8.2 community has been aggressively pursuing this high-level goal (although, as we note in the previous section, with more attention to the social and relational elements of socio-technical systems).

\subsubsection{Two Examples of Socio-Technical Theories of ICT}

In the rest of this section, we highlight two examples which represent some of the nascent work being done in the IFIP 8.2 community to move beyond declaring that things are socio-technical. The work of Crowston (2000) to advance a theory of process 
and Avgerou's (2002) work where she advances a broad-scale depiction of IS as innovation processes help us illustrate socio-technical theorizing. Both should be seen as starting points. ${ }^{13}$ Simply, these two examples are illustrative of socio-technical theorizing, not exclusive.

\subsubsection{Crowston: Theories That Link IS, Individuals and Processes}

Crowston (2000) argues that focusing on processes (conceptualized as sequences of activities) provides insight into the linkages among individual work and the larger work setting. Individuals perform the various activities that comprise the work done by the organization. A process focus is often used to analyze organizations. However, process theories can provide a means to link the activities in nonwork settings. For example, Frissen (2001) reports on the uses of cellular phones to manage the joint schedules of family members. This effort is detailed as a series of cases, each of which can be developed as a sequence of activities that demand coordination (some of which is enabled by the uses of ICT).

In process theories, uses of ICT are enacted by individuals who, through their actions, change the conduct of their work in response to the availability of these technologies. Therefore, ICT has to be conceptualized as combination of the technology and the process to which it is applied, what Orlikowski and Iacono refer to as "technology as embedded system" (2001, p. 126). It might be that ICT use makes individuals more efficient or effective at the activities they have always performed. For example, a manager using a spreadsheet to analyze a decision may be able to reach a conclusion more quickly or to consider more alternatives, thus improving the speed or quality of the process without changing the activities involved. A real estate agent might be able to search the database of house listings for each client every day instead of just occasionally. Yet, the same ICT used in the same process but in a different context (e.g., for a highly qualified and experienced agent dealing only in large mansions) might lead to fewer (if any) benefits.

In order to understand how changes in individual work might have a larger effect, Crowston argues that we must examine the ways that individual work changes relative to the process of which they are a part. To understand how individual work changes affect the process, it is necessary to examine the constraints on assembling activities that limit the possible arrangements and rearrangements of activities into processes. To identify these constraints, Crowston focuses in particular on the implications of dependencies between tasks for process assembly. For example, producer/consumer dependencies restrict the order in which activities can be performed, since the activity that consumes some resource (a piece of information, for example) can not be performed by the activity that produces it. Activities that are not involved in a dependency can be more easily rearranged. Beyond constraining the order of activities, dependencies often require additional activities to manage them. For example, Malone and Crowston (1994)

\footnotetext{
${ }^{13}$ There are, of course, other candidates for this discussion whose work may be known by members of IFIP 8.2 such as Ackerman's (2000) exploration of the social and technical in computer-supported cooperative work, Mansell's (2002) work on communication technologies and social change, Agre's (2003) work on the relationships among technical architectures and institutional structures, and Kling and McKim's (2000) socio-technical interaction networks.
} 
note that the producer/consumer dependency not only constrains the order of the activities (a precedence dependency), but may also require additional activities to manage the transfer of the resource between or to ensure the usability of the resource.

Precedence requires that the producer activity be performed before the consumer activity. This dependency can be managed in one of two ways: either the person performing the first activity can notify the person performing the second that a resource is ready, or the second can monitor the performance of the first. Here ICT may have an effect by providing a mechanism for cheap monitoring.

Transfer dependencies are managed by a range of mechanisms for physically moving resources to the actors performing the consuming activities (or vice versa). For example, inventory management systems can be classified here. Using ICT may alter both the mechanisms of transfer dependencies or the actors involved in transfer. Usability can be managed by having the consumer specify the nature of the resources required or by having the producer create standardized resources expected by the user (among other mechanisms). The roles of ICT in usability might be to help specify or standardize resources.

More generally, process models highlight the value of ICT as a means of change because many of the coordination activities in processes are primarily information processing. These activities are particularly susceptible to ICT-related changes. For example, increased information flow between the user and producer of a resource may make it easier for the user to convey specific needs, allowing the producer to create a more precisely tailored product. A process perspective is broadly applicable. For example, a process perspective can help us to explore and understand knowledge work and work processes, information flows such as exchanges of digital goods, and transorganizational interactions.

\subsubsection{Avgerou: ICT and Global Diversity}

In her treatise on IS and global diversity, Avgerou (2002) also depicts ICT as embedded in ensembles - although these ensembles are depicted as IS of a national or multinational scale. In contrast to the deterministic nature of process theorizing, she further promotes the variegated nature of the relations among an IS and its context as leading to "non-deterministic, non-essentialist view(s) of ICT..." (p. 231). Avgerou defines IS as innovation processes that unfold over time. This process of unfolding occurs through discourses and actions by mangers, technologists, users, and others. The process is erratic in that path dependencies are unclear; the innovation effort is intimately tied to events that unfold in particular situations and that have historical roots. These processes tend to reshape the thinking about, and the uses of, the IS and to the disenfranchisement of some participants.

In this forms of socio-technical theorizing, social contexts form the basis in which innovation processes unfold. This unfolding reflects a relationship among actors connected in a network of relations that both enable and constrain action. The temporal nature of this process and the relations among the actor network and that process are primarily driven by the context (and not some a priori force) in ways that can be locally justified and realized, but may seem chaotic and unpredictable if the contexts of action are not appreciated.

This form of socio-technical theorizing demands a critical analysis of the multiple institutions that make of the context and a depiction of the temporal process of 
innovation noting key events (both large and small scale) that together represent the way that the IS is depicted in discourse and through action. This analysis typically crosses several levels (e.g., connecting individual, organizational, and regional contexts and behaviors) and sets the technical elements of the IS within social contexts (focusing on collective uses and less on individual user behaviors ${ }^{14}$ ). The IS innovation process is thus represented as multiple paths, with the discourses and events used to both relate these paths and to depict the seemingly erratic process of negotiating multiple interests and agency over time. The critical orientation of her work is reflected in her highlighting that IS innovation efforts and "managerialist" thinking are often tightly linked, leading to disruptive processes and events.

Avgerou's critical theory of IS as an innovation process provides a means to reexamine normative conceptualizations of IS. We speculate that this might lead to alternative conceptualizations of IS and their effects (such as what Trauth and Jessup [2000] did regarding group decision support systems). A critical theory of IS will also provide a means to explore both large-scale innovations (such as ICT infrastructure studies) and small-scale deployments (such as work group and organizational implementations). Taking a non-managerialist perspective is also likely to raise questions on the power and effect of ICT (e.g., Clement 1994)

\subsubsection{Comparing the Approaches}

Crowston and Avgerou take different approaches to theorizing on the sociotechnical nature of ICT. Crowston's process model is analytic. Avgerou takes a critical approach to developing a contextual model of IS as an innovation process. However, both showcase principles of socio-technical change theory. Crowston reflects the seamless web principle by connecting the actions of individuals through process and showing how ICT can also link to process. Avgerou reflects the seamless web principle by developing the process of technical development with the pressures of the social and organizational context. Crowston's process theory approach reflects the principle of change of continuity though the mechanisms of process and coordination, while Avgerou's approach depicts the temporal nature of IT as a process of innovation. Both Crowston and Avgerou make it clear that technology is path dependent and its use is negotiated (in context or as it pertains to process decisions). Finally, both Crowston's and Avgerou's theorizing reflect the actor and structure principle. Crowston notes that processes are the larger structure that relates actors. Avgerou highlights the institutional nature of context and how these shape both individual behavior and the temporal process of IS innovation.

Crowston's process theory and Avgerou's critical innovation process theory advance socio-technical theorizing. However, what about their characterizations of ICT? Both reflect ensemble or functional conceptualizations, although the specific characteristics of this ensemble or functional view remain underdeveloped. So, these represent excellent starting points for advancing conceptualizations of ICT. We further speculate that the IS (and other related academic) community's interest in socio-

${ }^{14}$ Individual level phenomenacanbecentral, as Avgerou (2002, Chapter7)notes in the study of Cyprus' efforts to take on new IS in small manufacturing enterprises. The point is that individual behavior can only be understood within the contexts in which it occurs. 
technical theories of ICT is tied in part to the ability of these theories to provide additional insight into the social and the technical elements. It seems that too much of the insight of current socio-technical theories is on the social; the technical elements of these theories lags.

\section{SUMMARY}

Predicting the future is tricky, since we've not been there yet. ${ }^{15}$ Speculating on the future is more commonplace, and we do that here to engage the IS community, and our colleagues in the IFIP 8.2 community more specifically, to think about what we can do. In this paper we limited ourselves to speculating on two possible areas where we believe IFIP 8.2 community of scholars are well-positioned to advance our understanding of ICT in organizations and society: to advance conceptualizations of ICT and to better develop socio-technical theories of ICT. Moreover, we note that these two opportunities can be linked. For example, members of the IFIP 8.2 community might take on conceptualizations of ICT and use these as the basis for more robust socio-technical theories. Conversely, a socio-technical lens can be used to advance our conceptual understanding of ICT.

Better conceptualizations of ICT, and more powerful socio-technical theories, are likely to be needed as we engage in the debates on the design, development, implementation, policies of use, and implications of presence for a host of emerging technologies. For example, the growing interest in deploying broad-scale sensor networks, increasingly self-reliant and semiautonomous computing applications, powerful biometrics, a range of nano-technologies, and ever more pervasive and ubiquitous computing devices and computing applications are, as Winner(1986) notes, artifacts that embed politics. ${ }^{16}$

Theory often travels faster and further than does the empirical work on which it is often painstakingly constructed and we should strive to become theory "exporters" as Baskerville and Myers (2001) have suggested. We speculate that collective attention to both better developing (and perhaps expanding) our conceptualizations of ICT and theorizing on their socio-technical nature is the type of intellectual export that will attract scholars in related fields like information science, sociology, communications, medical informatics, and public administration units to our work. Implied in this speculation is that the effort in the next 25 years by the IFIP 8.2 community is to connect to likeinterested research communities.

Like all speculative scholarship, our argumentation is more about imagining possible directions than advocating for one particular view in opposition to all others. To this point, one strength of IFIP 8.2 scholarship is its diversity. So, in suggesting these two opportunities, we also decry attempts to constrain activities to these (or any other particular) directions. The innovative nature of the IFIP 8.2 research community is central to the value of the community's work. Our suggestions should be seen as a path that some in this community should take, leaving others to take other paths, or cut new

\footnotetext{
${ }^{15}$ As both Neils Bohr and Yogi Berri, among many, have noted....

${ }^{16}$ In particular, see Winner's chapter, "Do Artifacts Have Politics?” (pp. 19-39).
} 
paths. This considered speculation is directed at both stirring the community's collective mind and advancing the value of this community's work to interested others. In 2024, what do we want the future members of our community to say on the eve of the $40^{\text {th }}$ (and $20^{\text {th }}$ ) anniversary of the previous Manchester conference(s)?

\section{ACKNOWLEDGEMENTS}

Comments from Lynette Kvasny, Jim Jansen, Carleen Maitland, Andrea Hoplight Tapia, Duane Truex, and three anonymous reviewers have helped us to substantially improve this paper.

\section{REFERENCES}

Ackerman, M. "The Intellectual Challenge of CSCW: The Gap Between Social Requirements and Technical Feasibility," Human-Computer Interaction (15:2/3), 2000, pp. 181-205.

Agre, P. "The Architecture of Identity: Embedding Privacy in Market Institutions," Information, Communication and Society (2:1), 1999, pp. 1-25.

Agre, P. "Infrastructure and Institutional Change in the Networked University," Information, Communication and Society (3:4), 2000, pp. 494-507.

Agre, P. "Peer-to-Peer and the Promise of Internet Equality," Communications of the ACM (45:2), 2003, pp. 39-42.

Avgerou, C. Information Systems and Global Diversity, Oxford: Oxford University Press, 2002.

Baskerville, R., and Myers, M. "Information Systems as a Reference Discipline," MIS Quarterly (25:1), 2002, pp. 1-14.

Bijker, W. Of Bicycles, Bakelites, and Bulbs: Toward a Theory of Socio-technical Change, Cambridge, MA: MIT Press, 1995.

Bostrom, R., and Heinen, S. "MIS Problems and Failures: A Socio-Technical Perspective Part 1: The Causes," MIS Quarterly (1:3), 1977a, pp. 17-32.

Bostrom, R., and Heinen, S. "MIS Problems and Failures: A Socio-Technical Perspective Part 2: The Application of Socio-Technical Theory," MIS Quarterly (1:4), 1977b, pp. 11 -27.

Brynjolfsson, E., and Hitt, L. "Beyond the Productivity Paradox," Communications of the ACM (41:8), 1998, pp. 49-55.

Clement, A. "Computing at Work: Empowering Action by 'Low-Level Users'," Communications of the ACM(37:1), 1994, pp. 52-63.

Crowston, K. "Process as Theory in Information Systems Research," in R. Baskerville, J. Stage, and J. I. DeGross (Eds.), Organizational and Social Perspectives on Information Technology, Boston: Kluwer Academic Publishers, 2000, pp. 149-166.

Dutton, W. "The Web of Technology and People: Challenges for Economic and Social Research," Prometheus (17:1), 1999, pp. 5-20.

Ellis, D.; Allen, D.; and Wilson, T. "Information Science and Information Systems: Conjunct Subjects, Disjunct Disciplines," Journal of the American Society of Information Science (50:12), 1999, pp. 1095-1107.

Frissen, V. "ICTs in the Rush Hour of Life," The Information Society (16), 2000, pp. 65-77.

Giddens, A. The Constitution of Society: Outline of the Theory of Structure, Berkeley, CA: University of California Press, 1984.

Henderson, J., and Cooprider, J. "Dimensions of I/S Planning and Design Aids: A Functional Model of CASE Technology," Information Systems Research (1:3), 1990, pp. 227-254.

Hughes, T. Networks of Power, Baltimore, MD: The Johns Hopkins University Press, 1983.

Jones, M. "The Moving Finger: The Use of Social Theory in WG 8.2 Conference Papers, 19751999," in R. Baskerville, J. Stage, and J. I. DeGross (Eds.), Organizational and Social 
Perspectives on Information Technology, Boston: Kluwer Academic Publishers, 2000, pp. 15-32.

Keen, P. "MIS Research: Reference Disciplines and Cumulative Traditions," in E. McLean (Ed.), Proceedings of the First International Conference on Information Systems, Philadelphia, PA, 1980, pp. 9-18.

Kling, R., and Scacchi, W. "The Web of Computing: Computer Technology as Social Organization," Advances in Computers (21), 1982, pp. 1-90.

Kling, R., and McKim, G. "Not Just a Matter of Time: Field Differences in the Shaping of Electronic Media in Supporting Scientific Communication," Journal of the American Society for Information Science (51:4), 2000, pp. 1306-1320.

Lamb, R., and Kling, R. "Reconceptualizing Users as Social Actors in Information Systems Research," MIS Quarterly (27:2), 2003, pp. 197-235.

Latour, B. Science in Action, Milton Keynes, UK: Open University Press, 1987.

Lee, A. "MIS Quarterly Special Issue-Call For Papers: Intensive Research in Information Systems: Using Qualitative, Interpretive, and Case Methods to Study Information Technology," 1997 (available online at http://www.people.vcu.edu/ aslee/misq-sp-.htm).

Lee, A., and Liebenau, J. "Information Systems and Qualitative Research," in A. Lee, J. Liebenau, J. I. DeGross (Eds.), Information Systems and Qualitative Research, London: Chapman \& Hall, 1997, pp. 1-8.

Malone, T., and Crowston, K. "The Interdisciplinary Study of Coordination," Computer Surveys (26:1), 1994, pp. 87-119

Mansell, R. Inside the Communication Revolution: Evolving Patterns of Social and Technical Interaction, London: Oxford University Press, 2002.

Markus, M. "The Qualitative Difference in Information Systems Research and Practice," in A. S. Lee, J. Liebenau, and J. I. DeGross (Eds.), Information Systems and Qualitative Research, London: Chapman \& Hall, 1997, pp. 11-27.

McKenzie, D., and Wajcman, J. The Social Shaping of Technology (2 $\left.{ }^{\text {nd }} e d.\right)$, Philadelphia: Open University Press, 1999.

Morrison, J., and George, J. "Exploring the Software Engineering Component in MIS Research," Communications of the ACM (38:7), 1995, pp. 80-91.

Mumford, E. "Socio-Technical Design: An Unfulfilled Promise or a Future Opportunity," in R. Baskerville, J. Stage, and J. I. DeGross (Eds.), Organizational and Social Perspectives on Information Technology, Boston: Kluwer Academic Publishers, 2000, pp. 33-46.

Orlikowski, W., and lacono, S. "Desperately Seeking the 'IT' in IT Research-A Call to Theorizing the IT Artifact," Information Systems Research (12:2), 2001, pp. 121-124.

Palen, L. "Beyond the Handset: Designing for Wireless Communications Usability," Transactions on Human Computer Interaction (9:2), 2002, pp. 125-151.

Richardson, H. "CRM in Call Centres: The Logic of Practice," in M. Korpela, R. Montealegre, and A. Poulymenakpu (Eds.), Organizational Information Systems in the Context of Globalization, Boston: Kluwer Academic Publishers, 2003pp. 69-84.

Sawyer, S. and Chen, T. "Conceptualizing Information Technology and Studying Information Systems: Trends and Issues," in M. Myers, E. Whitley, E. Wynn, and J. I. DeGross (Eds.), Global and Organizational Discourse about Information Technology, Boston: Kluwer Academic Publishers, 2002, pp. 109-131.

Sawyer, S., and Tapia, A. "The Computerization of Work: A Social Informatics Perspective," in J. George (Ed.), Social Issues of Computing, New York: Oxford, 2003, pp. 93-109.

Scott, W. Institutions and Organizations, Thousand Oaks, CA: Sage Publications, 2001.

Simon, H. "Organizations and Markets," Journal of Economic Perspectives (5:2), 1991, pp. 2544.

Trauth, E., and Jessup, L. "Understanding Computer-Mediated Discussions: Positivist and Interpretive Analyses of Group Support System Use,” MIS Quarterly (24:1), 2000, pp. 123-156. 
Taylor, R. "The Value-Added Model," Chapter 4 in The Value-AddedProcesses in Information Systems, Philadelphia: Ablex Publishing Corporation, 1986, pp. 48-70.

Taylor, R. "Value-Added Processes in the Information Life Cycle," Journal of the American Society for Information Science (31:5), 1982, pp. 341-346.

Walsham, G. "Actor-Network Theory and IS Research: Current Status and Future Prospects," in A. S. Lee, J. Liebenau, and J. I. DeGross (Eds.), Information Systems and Qualitative Research, London: Chapman \& Hall, 1997, pp. 466-480.

Wastell, D. "Organizational Discourse as Social Defense: Taming the Tiger of Electronic Government," in M. Myers, E. Whitley, E. Wynn, and J. I. DeGross (Eds.), Global and Organizational Discourse About Information Technology, Boston: Kluwer Academic Publishers, 2002, pp. 179-196.

Weick, K. "Theoretical Assumptions and Research Methodology Selection," in F. W. McFarlan (Ed.), The Information Systems Research Challenge, Boston: Harvard Business School Press, 1984, p. 115.

Weick, K. "What Theory is Not: Theorizing Is," Administrative Science Quarterly (40), 1995, pp. 385-390.

Winner, L. The Whale and the Reactor: A Search for Limits in an Age of High Technology, Chicago: University of Chicago Press, 1986.

\section{ABOUT THE AUTHORS}

Steve Sawyer is a founding member of the Pennsylvania State University's School of Information Sciences and Technology. Steve holds affiliate appointments in Management and Organizations; Labor Studies and Industrial Relations; and Science, Technology and Society. Steve does social and organizational informatics research with a particular focus on people working together using information and communication technologies. Steve can be reached at sawyer@ist.psu.edu.

Kevin Crowston joined the School of Information Studies at Syracuse University in 1996. Before moving to Syracuse, he was a founding member of the Collaboratory for Research on Electronic Work at the University of Michigan and of the Center for Coordination Science at MIT. Kevin has published articles and book chapters in the area of information systems and new organizational forms. His current research interests include empirical studies of coordinationintensive processes in human organizations; theoretical characterizations of coordination problems and alternative methods for managing them; and design and empirical evaluation of new kinds of computer systems to support people working together. A specific example of the final interest is the application of document genre to the World-Wide Web. He can be reached at crowston@syr.edu.

\section{Appendix A}

\section{FIVE CONCEPTUALIZATIONS OF ICT}

The feature or tool view is the most common (or received) view of ICT. A tool view means that ICT is characterized as a collection of features that will operate as they were designed to behave. The roles of the ICT/features are seen as primarily technical in nature and direct in their effect. These feature-based approaches to studying ICT focus on the values, effects, and impacts of particular (and identifiable) technical aspects of an ICT. The resulting IS is thus an aggregation of the various features. When ICT are depicted as collections of features, people are characterized as both individuals and as social units, and the level of analysis is typically institutional. Feature- 
based ICT research is most often conducted as either a theory-building or intensive research effort. The ICT being studied is depicted as a moderating or mediating factor.

Conversely, the functional or ensemble view of ICT is one where specific artifacts and people are interdependently connected through roles, uses of information, and actions. In the functional view there is often an explicit attention on the ways of using a particular ICT. This conceptualization of ICT leads to so-called web models of IS in which people, their roles, their uses of and needs for information, and the computing elements (hardware and software) are connected together and embedded in a larger social milieu (Kling and Scacchi, 1982). When ICT are conceptualized as functions or ensembles, people are depicted as social actors. The research is typically structured as a cross-level analysis, but at varying aggregate levels. The ICT being studied is often depicted in terms of functionality provided through use.

The proxy view of ICT is that some (often quantified) surrogate can capture or measure the value of ICT. For example, a researcher might use IS budgets as a proxy for the level of ICT in use. Proxy views of IS and ICT focus on making clear the ways in which the measure highlights the value of the ICT or IS. The computational view of ICT focuses on the computational power or abilities of an artifact. This approach highlights the construction of a computational artifact, where that artifact instantiates an idea or theory. Finally, nominal treatments of ICT are those where a study mentions ICT without actually including it in the study. 